\title{
Pedagogical Potentials of IEEE 802.11 WLAN to Nigerian Universities: A Case Study of the University of Uyo
}

\author{
Inuwa Musa Hassan, Habib Ullah Khan, and V. V. Madhavi Lalitha
}

\begin{abstract}
The research on 'Pedagogical potentials of IEEE 802.11 WLAN to Nigerian Universities-A case study of University of UYO' is an in depth study to evaluate the potentials of its implementation to the entire teaching and tutoring vertical in Nigerian universities. While conducting this research study, the campus did not have the facility of Wireless internet service. Researchers are to provide the WLAN-Wireless local area network service to support the communication protocol limiting to shorter distances within a definite range with aid of infrared signals and radio networks. For this study, data collection is made over two periods, i.e., first, at the time of launching WLAN in order to gain an overview of the academic performance of the students and in the second instance, after providing the training to use WLAN, at the end of the semester. This study is conducted over a period equivalent to one semester. The objective of this is to identify any improvements in the performance of the students and the teaching staff after the completion of the training. The key performance indicator 'Academic outcome / Performance of students and attitude of faculty' on wireless internet in the campus is captured through the study and relevant statistical tools and techniques are applied to the data. The ascent in the academic outcome of students and the performance ofthe faculty is evident for the benefit of WLAN technology.
\end{abstract}

Index Terms-Information and communication technology (ICT), pedagogy, wireless local area networks (WLAN), Wi-Fi (wireless fidelity).

\section{INTRODUCTION}

Over the decades, information and technology have steered the change in enabling individuals in adopting the technology through 'Information and Communication Technology [ICT] and especially by accessing the World Wide Web which, in turn, changed the lives of all [1], [2]. Internet has enabled all to use the technology at a much faster pace than expected [3], [4] and [5]. It has completely changed the methodology of communication from the legacy to the most advanced portal. Orthodoxically, the course material is couriered to the students. After adapting to the information and communication technology, the study material is made available online so that students can access them over internet. Also, the universities made the study materials available over a secured portal. The education sector also has followed the

Manuscript received July 28, 2014; revised November 19, 2014

Inuwa Musa Hassan is with the Department of Computer Science, Laureate Online Education/University of Liverpool, UK (e-mail: imhassan@inuwa.net).

Habib Ullah Khan is with Accounting and Information Systems Department, Qatar University, Doha, Qatar (e-mail: habib.khan@qu.edu.qa).

V. V. Madhavi Lalitha is with Hamad Medical Corporation, Qatar (e-mail: jinugumadhavi@gmail.com). suit. Instant messaging and use of electronic mails aid the students to clarify their concerns with the faculty. After adopting the information and communication technology, the study material is made available online so that students can access them over internet and can share with each other using online collaborative tools [6], [7]. Instant messaging and use of electronic mails aid the students to clarify their concerns with the faculty in normal classes as well as in new mode of blended learning [8].

The Internet, therefore, has been recognized to improve academic performance of students on campuses [9], [10]. The IEEE 802.11 protocols, through wireless local area networks (WLAN), will further change the landscape of campus pedagogical practices. Appropriate mix of devices in a wireless network has been postulated to facilitate enhanced pedagogy and learning experience [11], [12]. Not only that, the academic productivity of students is known to depend on, among other variables, available resources [13]-[15]. Wireless Internet is arguably among the best of these resources. However, specifically how the IEEE 802.11 protocols impact the traditional way of lecture delivery without access to the internet in the classrooms in Nigerian university campuses through the wireless Internet has not been adequately investigated.

\section{A. Objective}

The objective 'To study the impact of Pedagogical potentials of IEEE 802.11 WLAN to Nigerian Universities with a case study model of University of Uyo', the data collected in two phases. This is to establish the performance of students and faculty during the first phase- when WLAN is launched prior to provision of access and relevant training on its usage and during the second phase- after three months of raining on WLAN usage with Likert scale method adopted for questionnaires. The first phase shot off when the researchers started this study initiated the use of WLAN to students and faculty in the university. The second phase of data collection is executed after three months (post access) to ascertain the use and adoption of WLAN in the campus across the university administrative offices, libraries and access to students with online portals with respect to the course material.

The impact of WLAN is studied with help of questionnaires and analysis is performed by using correlation and regression tools. Online survey questionnaires are also used to obtain the data (Survey monkey).The network covered the lecture rooms, faculty offices, the Engineering Library and the students' hostels. This provided the required resources for the students and faculty. The results revealed through KPIs that the academic performance of the students' 
has increased from $\mathrm{C}$ grade to $\mathrm{B}$ grade after the exposure of students to the wireless Internet (WLAN) and the faculty assessment also proved the same. Few instances are recorded where in the students and the lecturers have recorded weak dependence to WLAN in correlation coefficient analysis. A marginal ascent in the academic performance is noticed. The study also disclosed the stringent need to educate the users thoroughly to elevate their interest levels towards WLAN and its usage.

\section{LITERATURE REVIEW}

IEEE 802.11 standard and its subsequent amendments and revisions found their roots from the original standard which appeared in 1999 and reaffirmed in 2003 [16]. The technology specified by 802.11 is for medium access control (MAC) and several physical layers (PHY) to wirelessly connect fixed, portable and moving stations (STAs) within a local area network [17]. This has far-reaching revolutionary effects in the way information is shared by enabling seamless connectivity among the portable devices into a wireless fidelity (Wi-Fi) network otherwise called wireless local area network (WLAN) [18], [19]. Because of the enormous potentials presented by WLAN for information sharing, opportunities are explored to leverage those potentials offered by the technology and its concomitant devices to pedagogy at all levels of education including research. For example, an experiment with WLAN in a field study is conducted on the Colorado Plateau to find out participants' perceptions while using WLAN and the technology adopted (portable computing devices) [20].

This technology is considered well enough for enhancing seamless communication integration over online portals and act as a tool for enhancing scientific inquiry. Wireless interactive teaching system (WITS) facilitates active learning and this study is revealed positive impacts on the students [21]. Researches noticed that variables such as previous experience and demography contributed to the results on a major note. However, technology as one of the attribute did produce positive effects in learning. Many of these studies in Internet potentials impacted the learning experience in higher education and revealed the effect on 'how' instead of 'what' wireless access are utilized for. A study surveyed the Internet usage pattern by students and faculty of three engineering colleges in India and investigated the purpose of their usage [22]. The study also tested whether online resources available over internet could replace the college libraries. Additionally, experiences of faculty and lectures about internet usage are captured along with the impact of wireless Internet. The research is conducted by distributing laptops to students and faculty [23]. Results revealed positive effects-and significant change in the teaching methodology of the faculty. An identical study investigated the potentials of the deployment of 802.11 wireless technology for academic activities showed prominent improvement and enhancement in collaborative learning in higher education setting [24].

A study conducted at the Norwegian University of Science and Technology (NTNU) focused on the potentials of mobile phones through WLAN to students learning capacity by encouraging them to access "topic knowledge" prior to attending lectures [25]. The study surveyed as to how the students used portable devices to connect to the University's academic portal, the Learning Management System (LMS) and to access instructional materials including videos before attending the corresponding module lectures. The results revealed the excitement of the students at the new technology as well as specific positive impacts on their "learning activities" such as "active participation" during lectures.In order to encourage the students for accessing the "topic knowledge" [25], a combination of hardcopies and online reference materials are encouraged in 'context-aware' model [26], [27]. Context-aware model is a novel methodology that is meant to overcome the drawbacks of traditional approach of delivering instructional materials and to provide adaptive support to the students based on their learning traits [28]. This system can identify users by using variables such as IP addresses of their access nodes to deliver relevant instructional materials as per their personal learning needs [29]. Also, this technology enables students to interact with digital material as they do with their faculty in traditional method. The best supporting means for accessing the digital material are the portable devices which are handy and supportive not only for context-aware methodology but also for m-learning.

An interesting study surveyed the perception of the students in using small portable devices for m-learning and concluded that "mobile learning is widely embraced" by the students because of the ease in access irrespective of location within the University [30].

\section{A. Scenario of Nigeria}

Abundant research work revealed that either in the Nigerian context or in its universities, the deployment of WLAN is scanty. The level of utilization of Internet at a Nigerian university is tested and reported that only $17.26 \%$ accounted for accessing research material [31]. This means utilization of Internet for pedagogy is very low. Another study revealed that $92 \%$ usage of internet which accounted for spending an online mean time of $3.5 \mathrm{hrs} /$ week [32]. This shows an exponential growth in the use of Internet among the academic communities in Nigeria.

Ref. [33] contradicted with the finding of [32] by reporting that only $27.7 \%$ of graduate students and $62.4 \%$ of staff used the Internet. A related study in South-Western universities found that as high as $54-79 \%$ of faculty members have published more research work, attended conferences, and improved teaching due to the usage of the Internet [34]. This finding is in consensus with that of [33] cited above. Another investigation from a North-Eastern university reported that students had significant impact on their academic performance as a result of using the Internet, albeit not wireless [35].

Other studies also indicate that, while the Internet is well appreciated and found to be significantly useful, the efforts to deliver such technology using wireless fidelity (Wi-Fi) are very meek. The emphatic efforts of Nigerian universities to uplift this situation of Wi-Fi usage by re-engineering their ICT policies [36] can leverage the spread of technology of 802.11 WLAN to reap the benefits with high scalability and low budget. This will help clean up the clustered cyber cafes 
in the universities [37].

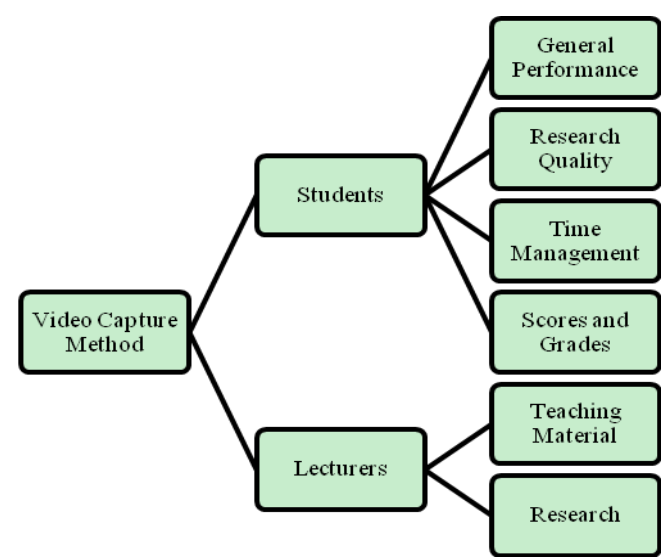

Fig. 1. Model to establish the relation between dependent and indt. variables.

\section{METHODOLOGY}

The study investigates the pedagogical potentials of 802.11 WLAN to universities in Nigeria using the University of Uyo as the unit of analysis. Since there is no WLAN while conducting this study, it necessitated to provide new wireless internet service. The reach of the WLAN covered the classes, the faculty offices, the Engineering Library as well as the students' hostels; all in the University's new campus site. The WLAN is available 24 hours a day. Power is supplemented with an $800 \mathrm{KW}$ Inverter during public electricity outages.

Having gone through the extol literature, the following research questions are framed for the present study to investigate the pedagogical potentials of 802.11 WLAN to universities in Nigeria using the University of Uyo.

\section{A. Research Questions}

1) Is there any improvement in the academic performance of the students with the help of wireless access?

2) Is there any improvement in the instructional materials and research outputs of the faculty members using wireless internet?

To answer the above research questions, the following hypotheses are made.

\section{B. Hypothesis}

1) H01: There is no significant improvement in the academic performance of students with the help of WLAN access.

2) H02: There is no significant improvement in usage of instructional materials and research outputs through WLAN

\section{Data Collection}

Data are collected in two phases. The first phase is when the WLAN is launched for the first instance by the researchers for the purpose of the study and the second phase is after the students and faculty had used the network for three and half month duration. The objective in first phase is to establish the academic performance levels of the students and productivity of the lecturers prior to an extended exposure to wireless Internet; and the objective in second phase is to measure performance transformation that might have occurred. Two sets of questionnaires are administered among the lecturers and students of the Faculty of Engineering. First pair of of questionnaires, one each for the students and for the lecturers is administered after three weeks of the WLAN service opened for the use. Data collection for this phase continued two weeks. We have used a number of questions conforming to Likert Scale in both students' and lecturers' questionnaires because of their potential accuracy in analysis [38]. The rest of questionnaires are formulated to probe frequencies and percentages of different key variables. These questionnaires are administered using the project's Wi-Fi via www.surveymonkey.com and in hardcopies. However, the researchers also created a website from which links to the questionnaires at www.surveymonkey.com are provided. The project website is www.inuwa.net which is made available to request students and lecturers to voluntarily follow the links to answer the questionnaires.

\section{DATA ANALYSIS}

The two-stage data collection approach is required in order to establish the initial performance levels of different variables explored by the questionnaires and to compare the results with those obtained for the same set of variables at the end of the study. This clearly exposed performance transformation that took place during the course of the study, especially among the students. Careful analysis of this transformation portrayed the improvement levels and acceptability of 802.11 WLAN in the university.

Pearson Correlation is used to analyze relationships between Likert Scale-type questions. For example, when the students and the lecturers are asked "of how much help are the sources they used 'most' for their research and teaching?", the scale of the answers is: Excellent, Very Good, Good, Poor, and Very Poor. and when the students are asked "Of how much help are the sources they could use in their research?", the answers are: Extremely Helpful, Very helpful, Moderately Helpful, Slightly Helpful, Not at all Helpful - all typical of Likert Scale questions.

\section{A. Internet Resources Accessed}

The informational resources accessed by both the lecturers and students are the open-access information on the internet, browsed via the search engines. This is evident from analysis of the data collected during the first phase. Specifically, during the first time both the lecturers and students responded to the questionnaires, $76.2 \%$ and $73.1 \%$ respectively used the open-access information on the internet most. The results during the second phase revealed that $86.1 \%$ of lecturers and $61.3 \%$ of students used the open-access via search engines. This shows that the percentage of the students using the free resources has declined, but the number of respondents in the second instance is much bigger, as previously stated.

\section{B. WLAN Impact on Academic Quality}

An evaluation of the data collected from the first questionnaire survey shows that both lecturers and students averred that information they accessed using the WLAN is generally 'very helpful'. For the first phase of data collected, $85 \%$ of lecturers averred that the information they accessed via the WLAN is 'very good', $10 \%$ said 'excellent', and $5 \%$ 
said 'good'. For the students, the information sources are 'very helpful' (36.2\%), 'extremely helpful' (24.5\%), and 'moderately helpful' (28.2\%). Only $1.8 \%$ of students said they are not helpful at all. Analysis of the responses revealed that $54.3 \%$ of lecturers agreed that WLAN has indeed helped them to prepare teaching and instructional materials for their students.

The students are asked to rate the WLAN using different variables of academic performance. For example, on:

\section{General Performance}

$41 \%$ said that WLAN has helped them found better references, $32.7 \%$ understood the subject matter better, $20.7 \%$ gbetter grades, $3.7 \%$ gotverbal commendation and for $4.1 \%$, research is Easier.

\section{Research Quality}

90.6\% of students said that the WLAN has improved their research quality with $34.75 \%$ of them rating it good; $43.7 \%$ very god, and $12.2 \%$ excellent. However, $8.1 \%$ rated it poor and $1.4 \%$ very poor.

\section{E. Time Management}

Most students said the WLAN has saved them time of online search or research by more than $81 \%(8.1 \%$ of students); by more than $61 \%$ (32.6\% of students); and by more than $41 \%$ (37.6\% of students). The rest, $21.7 \%$ of the students said it saved them less than $40 \%$ of their time.

\section{F. Scores and Grades}

Out of 220n of students that answered this question, $33.6 \%$ said the WLAN has improved their grades by more than $61 \%$; while $22.3 \%$ said by more than $41 \%$. That is about $60 \%$ of the students saying that their grades improved by more than $41 \%$. Specifically the nitty-gritties of this aspect are not very much probed in by this research, because of the limitations. But the correlation and dependency of these performances with the WLAN access are evaluated.

\section{G. Improved Academic Performance of Students - Assessed by Students}

The students are asked to evaluate themselves, before and after WLAN usage for 3 months, as far as academic performance is concerned, by choosing one of A, B, C, D or E grades, with ' $A$ ' being the best. Fig. 2 brings together these two ratings. When the students did not use the WLAN at the campus and there is no internet service for them, majority $(37 \%)$ rated themselves as ' $C$ ' grade students, followed by ' $B$ ' students (34\%) and ' $A$ ' students (24.7\%). This did change for the better when they rated themselves after they had used the WLAN for few months. Majority of them (43.2\%) rated themselves as ' $\mathrm{B}$ ' grade students; while $34.2 \%$ saw themselves as ' $A$ ' grade students. Thus, the bulk of them transformed from seeing themselves as ' $\mathrm{C}$ ' grades to ' $\mathrm{B}$ ' grade students.

\section{H. Improved Academic Performance of Students - Assessed by Lecturers}

To cross-check the students' opinions on their performance, lecturers are also asked to rate the students on key academic performance variables viz., Research Assignments, Tests, End of Semester Exams, Seminars, Projects, and Referencing.
This is collected before the students used the WLAN at the campus.After they used WLAN for an extended period of time, the lecturers areagain asked to rate the students; but this time based of four key variables; viz., Assignments, Seminars, Tests, and Referencing only because the semester examination just commenced and the results are not yet released. These two figures considered the number of times lecturers chose each of the above variables. The results are juxtaposed together in Fig. 3. We note that 21 of 24 lecturers answered this question for the first questionnaire, and 36 of 37 of them for the second questionnaire, making it $92.34 \%$ of them; and only $7.66 \%$ skipped the question. It is therefore evident that the results agreed to a great extent with the results of the students' rating about their own academic performance depicted in Fig. 2 above.

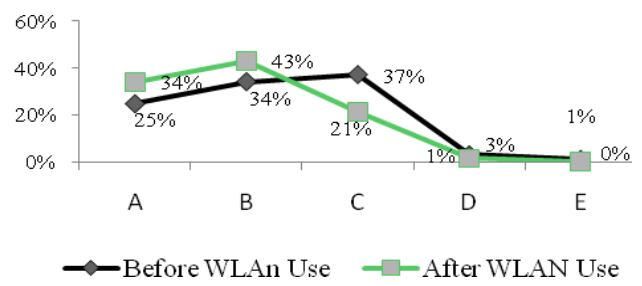

Fig. 2. Student's rating of their performance before and after WLAN use.

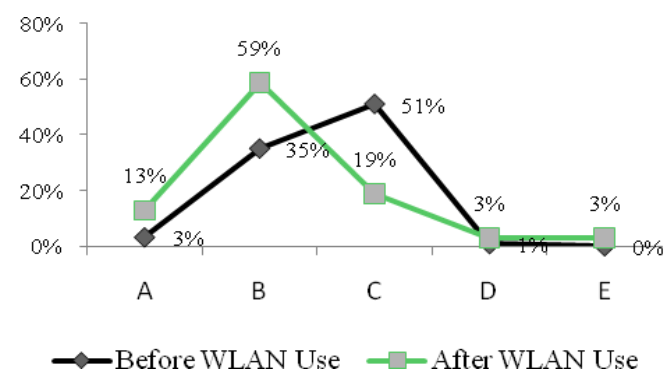

Fig. 3. Students' academic performance rating by lecturers.

\section{Correlation Dependencies}

When we tested the relationship between the students' assessment of their performance before the WLAN access on one hand, and after the WLAN access on another (Fig. 2), Correlation coefficient analysis revealed a very strong relationship ( $r=0.833$ ). For the lecturers, the correlation between their assessment of the students before and after WLAN access is found to be strong $(r=0.601)$. The specific domains of these assessments are given in Fig. 4.

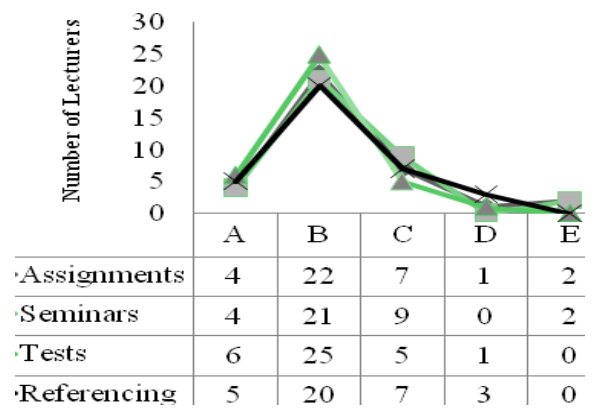

Fig. 4. Rating of students' performance by lecturers after WLAN use.

However, when we tested the relationship between the WLAN access levels on a Likert Scale type questions with students' research quality post exposure to WLAN, we found 
a strong correlation $(r=0.724)$. But, the relationship between their access to WLAN and the academic performance in continuous assessment especially term papers, assignments and tests is found to be a weak one $(r=0.217)$. This is surprising if contrasted with the very strong correlation we found above of their opinions that they have improved from being $\mathrm{C}$-grade to B-grade students.

\section{J. Lecturers' Version}

Though the lecturers indicated that they use the internet for their research work, we found a weak correlation $(r=0.378)$ between their reported internet access and their research throughputs, while correlation between the WLAN access on the campus and their research throughputs is found negative and weak $(r=-0.355)$. Their research throughputs, therefore, did not change during the period WLAN is provided for them at the campus. A strong correlation $(r=0.786)$ is found between their throughputs before and after WLAN is provided for at least 3 months, demonstrating thereby that not much has changed in their publishing frequency. This is further demonstrated by a negative correlation $(r=-0.632)$ between their WLAN access and their preparation of instructional materials such as handouts and lecture notes, even though $54 \%$ of them said they did use it for that purpose. This contrasts with an earlier study [23] that found positive effects of wireless Internet on teachers. Equally interesting is the lecturers' attitude towards the online scholarly journal databases which included EBSCO host, Questia and LexisNexis subscribed by the University Library of which only $5 \%$ said they used the resources; with most of them (76\%) preferring open access information on the Internet. Consequently, there is no evidence to suggest that access to wireless Internet network played any role in lecturers' research throughput. During the first survey, for example, more lecturers $(35 \%)$ published semi-annually. This changed the annual throughputs $(47.2 \%)$ in the second survey as can be seen from Fig. 5 below. It is noteworthy, however, that $24 \mathrm{n}$ and $37 \mathrm{n}$ of lecturers responded to the first and second questionnaires respectively.

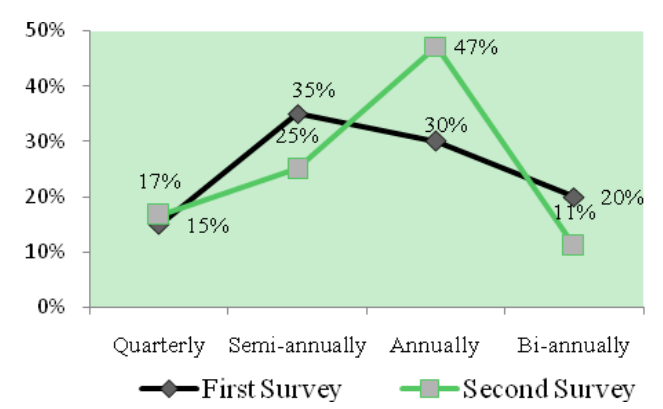

Fig. 5. Lecturers' frequency of research publication.

\section{DISCUSSION}

IEEE 802.11 WLAN has demonstrated positive impacts on students' learning and improved academic performance as noted, confirming an earlier study that reported positive impact of wireless Internet on students [21]. This is evident from assessments reported by their lecturers before and after wireless use with a strong correlation $(r=0.601)$. Also, the students $(73 \%)$ and lecturers $(76 \%)$ preferred free open-access information on the internet while moving away from the online databases subscribed by the university library. The impact of WLAN across academic performance assessments of students is also pronounced. For example, $90 \%$ of students reported improvements in research quality $(r$ $=0.724), 81 \%$ in time management, $61 \%$ in scores and grades. However, as noted above, though students expressed very high optimism that their grades did improve, a weak relationship correlation $(r=0.217)$ is found between their WLAN access and their improved grades.

However, lecturers did make little use of the WLAN available at their disposal in their offices. As a result, their research throughput is not positively impacted by the WLAN as opposed to an earlier study [34] which noted that lecturers improved productivity by using Internet. But this study strictly covered a period of three months, equivalent to one academic semester and therefore investigated the performance during that period only. Hence lecturers needed to invest a lot of time and interest in order to benefit from an important resource such as WLAN for their pedagogical work.

It is noteworthy that both the lecturers and students of the Faculty of Engineering had very low awareness of the online resources available to them via the University Library. The Engineering Library had URLs of these databases printed on paper with instructions on how to access them. The WLAN caused awareness especially among the students about the existence of these online databases. In general, the results show an interesting divergence of attitudes between the students and their lecturers towards wireless internet in the campus.

\section{CONCLUSION}

Great potentials of IEEE 802.11 WLAN to pedagogy in Nigerian universities are evident from the results of the study conducted at the University of Uyo. Students' academic performance is positively impacted along key performance indices. Students' performance rating before and after exposure to wireless Internet (WLAN) transformed from C-grade to B-grade both from the students' and lecturers' assessments. However, some performance domains, such as tests of students and research publications of lecturers recorded weak dependence on WLAN in correlation coefficient analysis. The study also found lack of interest both from students and their lecturers towards the rich digital resources of academic journals subscribed by the University Library and made available online. This is attributed to lackof awareness of the availability of these databases at the new campus.

\section{REFERENCES}

[1] R. E. Obiadazie, "Application of information and communication technology (ICT) in teaching and learning process of students with disabilities," An International Journal of Science and Technology, vol. 3, no. 1, pp. 176-196, February 2014.

[2] H. U. Khan, S. Ahmed, and M. Abdollahian, "Supply chain technology acceptance, adoption, and possible challenges: A case study of service organizations of Saudi Arabia," presented at 10th International Conference on Information Technology: New Generations, Las Vegas, Nevada, USA, April 15-17, 2013. 
[3] M. A. Awan, H. U. Khan, and W. Zhang, "A comparative study on Online Service Quality Perception of two Major Regional Economies," International Journal of e-Education, e-Business, e-Management and e-Learning(IJEEEE), vol. 2, no. 6, p. 529, December 2012.

[4] L. Stosic and M. Bogdanovic, "M-learning - A new form of learning and education," International Journal of Cognitive Research in Science, Engineering and Education, vol. 1, no. 2, 2013.

[5] H. U. Khan and M. N. Faisal, "A grey based approach for ERP vendor selection in small and medium enterprises in Qatar," Int. J. of Business Information Systems (IJBIS), 2014

[6] S. Hadjerrouit, "Wiki-based collaborative learning in higher education: A pedagogical evaluation," International Journal of Innovation and Learning, vol. 12, no. 1, pp. 6-26, 2012.

[7] R. J. Galvin, "Peer support: Enhancing the online learning experience," Int. J. of Innovation and Learning, vol. 12, no. 1, pp. 41-53, 2012.

[8] K. C. Li, "Encountering pedagogical challenges: A case of three pilot blended learning courses," Int. J. of Innovation and Learning, vol. 13 , no. 2, pp. 153-165, 2013.

[9] S. P. Adegoke, "Effect of internet browsing on students' academic achievement at the senior secondary school level," International Journal of Evaluation and Research in Education, vol. 2, no. 3, 2013.

[10] H. U. Khan, "Role of computer mediated communication in affect empowerment and performance improvement," vol. 3, no. 3, p. 165, July 2013.

[11] A. E. Halabi, A. Hachem, L. Al-Akhrass, H. Artail, and H. U. Khan, "Identifying the linkability between web servers for enhanced internet computing," presented at 17th IEEE Mediterranean Electrotechnical Conference MELECON 2014, Beirut, Lebanon, April, 13-16, 2014.

[12] Y. Qiang, "Applying wireless classroom to build a highly interactive learning environment," Cognitive Education, vol. 3, no. 4, pp. 527-532, 2012.

[13] L. F. Gamboa, M. Rodriguez, and A. F. Garcia, "Differences in motivations and academic achievement," Lecturas de Economía, no. 78, pp. 9-44, 2013

[14] H. U. Khan, "Computer mediated communication, quality of learning, and performance," Journal of GSTF Business Review, vol. 1, no. 3, 2012.

[15] A. Sheil and C. M. Bahk, "Exploring the pedagogical outcomes of service learning in international public relations education," International Journal of Innovation and Learning (IJIL), vol. 7, no. 3, pp. 274-289, 2010

[16] Institute of Electrical and Electronic Engineers (2012) IEEE Std 802. IEEE Explore. [Online]. Available: Doi: 10.1109/IEEESTD.2012.6178212.

[17] A. Heindl and R. German, "Performance modeling of IEEE 802.11 wireless LANs with stochastic Petri nets," Performance Evaluation, vol. 44, no. 1, pp. 139-164, April 2001.

[18] S. Banerji and R. S. Chowdhury, "Recent development in IEEE 802.11 WLAN technology," International Journal of Mechatronics, Electrical and Computer Technology, vol. 3, no. 9, pp. 1001-1013, October 2013.

[19] M. Nekovee and R. S. Saksena, "Simulations of large-scale WiFi-based wireless networks: Interdisciplinary challenges and applications," Future Generation Computer Systems, vol. 26, no. 3, pp 514-520, March 2010.

[20] P. Cantrell and M. S. Knudson, "Using technology to enhance science inquiry in an outdoor classroom," Computers in the Schools, vol. 23 no. 1-2, pp. 7-18, 2006

[21] C. Eckel, C. Rojas, and S. B. Ball, "Technology improves learning in large principles of economics classes: Using our WITS," American Economic Review, vol. 96, no. 2, pp. 442-446, May 2006.

[22] R. Kumar and A. Kaur, "Internet use by teachers and students in engineering colleges of Punjab, Haryana, and Himachal Pradesh States of India: An analysis," Electronic Journal of Academic and Special Librarianship, vol. 7, no. 1, 2006.

[23] K. Burns and J. Polman, "The impact of ubiquitous computing in the internet age: How middle school teachers integrated wireless laptops in the initial stages of implementation," Journal of Technology \& Teacher Education, vol. 14, no. 2, pp. 363-385, 2006.

[24] S. Jarvela, P. Naykki, J. Laru, and T. Luokkanen, "Structuring and regulating collaborative learning in higher education with wireless networks and mobile tools," Educational Technology \& Society, vol. 10 , no. 4, pp. 71-79, 2007

[25] M. Rismark, A. Solvberg, A. Stromme, and L. M. Hokstad, "Using mobile phones to prepare for university lectures: student's experiences," Turkish Online Journal of Educational Technology, vol. 6, no. 4, pp. 85-90, 2007.
[26] H. U. Khan, "Use of e-learning tools to solve group work problems in higher education: A case study of gulf countries," The Advances in Computer Science: An International Journal (ACSIJ), vol. 2, no. 3, p. 90, July 2013

[27] G. D. Chen and P. Y. Chao, "Augmenting traditional books with context-aware learning supports from online learning communities," Journal of Educational Technology \& Society, vol. 11, no. 2, pp 27-40, 2008

[28] G. J. Hwang, C. C. Tsai, and S. J. H. Yang, "Criteria, strategies and research issues of context-aware ubiquitous learning," Educational Technology \& Society, vol. 11, no. 2, pp. 16-26, 2008.

[29] Z. Aziz, C. J. Anumba, and F. Pena-Mora, "Using context-aware wireless technologies to support teaching and learning in built environment," International Journal of Construction Education \& Research, vol. 6, no. 1, pp. 18-29, March 2010.

[30] S. M. Jacob and B. Issac, "Mobile technologies and its impact - An analysis in higher education context," International Journal of Interactive Mobile Technologies, vol. 2, no. 1, pp. 10-18, 2008.

[31] K. O. Jagboro, "A study of internet usage in Nigerian universities: A case study of Obafemi Awolowo University, Ile-Ife, Nigeria," First Monday, vol. 8, no. 2, February 2003.

[32] M. O. Awoleye, W. O. Siyanbola, and O. F. Oladipupo, "Adoption assessment of Internet usage amongst undergraduates in Nigeria universities - A case study approach," Journal of Technology Management \& Innovation, vol. 3, no. 1, pp. 84-89, 2008.

[33] O. O. Bola and O. O. Ogunlade, "Accessibility and utilization of internet service by graduate students in University of Lagos, Nigeria," International Journal of Humanities \& Social Science, vol. 2, no. 17 , pp. 254-258, September 2012.

[34] E. E. Okafor, D. Imhonopi, and M. U. Urim, "Utilisation of internet services and its impact on teaching and research outputs in private universities in South-Western Nigeria," International Journal of Emerging Technologies \& Society, vol. 9, no. 2, pp. 135-151, 2011.

[35] P. M. Ogedebe, "The relationship between academic performance and internet services in tertiary institutions: A case study of the university of Maiduguri, Nigeria," Journal of Mathematics \& Technology, no. 3, pp. 105-115, 2010

[36] J. K. Fasae and F. R. Aladeniyi. (2012). Internet use by students of faculty of science in two Nigerian universities. Library Philosophy and Practice. [Online]. Available: http://www.webpages.uidaho.edu/ mbolin/fasae-aladeniyi.htm.

[37] E. D. Chigbu and C. L. Dim. (January 2012). Connectivity and accessibility in Nigerian university libraries: A survey of access, usage, and problems in the University of Nigeria, Nsukka. Library Philosophy \& Practice. [Online]. pp. 1-16. Available: http://digitalcommons.unl.edu/cgi/viewcontent.cgi?article=1841\&con text=libphilprac.

[38] J. L. Rasmussen, "Analysis of likert-scale verticals of healthcare data: A reinterpretation of gregoire and driver," Psychological Bulletin, vol 105 , no. 1 , pp. $167-170,1989$

Inuwa Musa Hassan is a Nigerian citizen and is affiliated with the Department of Computer Science, Laureate Online Education/University of Liverpool, UK.

Habib Ullah Khan is the corresponding author of this paper. Dr. Khan is a Canadian citizen and is working as a faculty of MIS in the Department of Accounting and Information System, College of Business and Economics, Qatar University, Doha, Qatar. He completed his Ph.D. degree in management information systems from Leeds Metropolitan University, UK He has nearly 16 years of industry, teaching and research experience. His research interests are in the area of IT adoption in supply chain management, ERP systems, mobile commerce, computer mediated communication, IT outsourcing, and IT security.

Madhavi Lalitha is a research coordinator at Hamad Medical Corporation, Qatar. She is an Indian national and pursing her Ph.D. in developmental sciences. She also has vast experience in many healthcare domains and is an academician. She is awarded master of philosophy (M. Phil) in developmental sciences from Centre for Economic and Social Sciences, Hyderabad, India and has dual masters in statistics and in busines administration as well. Her areas of interest are in applied statistical modeling and data analytics in the areas of healthcare research, information technology, healthcare services and social sciences. 